\title{
A economia política da produção capitalista do espaço em Neil Smith
}

\section{Nelson Diniz}

\section{Resumo}

Neil Smith foi um dentre aqueles autores do movimento de renovação crítica da Geografia que mais se aproximaram do marxismo como alternativa teórica e metodológica aos fundamentos tradicionais dessa disciplina. Seu trabalho envolve, concomitantemente, a renovação teórica dos conceitos de natureza, de espaço e de desenvolvimento desigual e a preocupação com a articulação lógico-histórica entre eles. Este artigo procura refletir sobre as transformações do conceito de espaço e a ressignificação das noções de espaço absoluto e espaço relativo levada a cabo pelo autor com o objetivo de compreender a produção capitalista do espaço.

Palavras-chave: espaço absoluto; espaço relativo; produção do espaço.

\section{Resumen}

Neil Smith ha sido uno entre los autores del movimiento de renovación crítica de la Geografía más cercano del marxismo como alternativa teórica y metodológica a los fundamentos tradicionales de la disciplina. Su trabajo implica, simultáneamente, la renovación teórica de los conceptos de naturaleza, espacio y desarrollo desigual y la preocupación con la articulación lógicohistórica entre ellos. Este artículo pretende reflexionar sobre la transformación del concepto de espacio y la resignificación de los conceptos de espacio absoluto y espacio relativo realizada por el autor con el objetivo de comprender la producción capitalista del espacio.

Palabras clave: espacio absoluto; espacio relativo; producción del espacio.

\section{Introdução}

A Geografia, ao menos desde a década de 1970, esteve marcada por um rico movimento de renovação crítica. De início, a renovação pretendia desvendar o comprometimento ideológico da Geografia que se produzira até então. Diversos autores se empenharam em compreender e denunciar o papel que a chamada Geografia Oficial cumpriu ao colocar-se a serviço da 
reprodução das relações sociais dominantes. Alguns autores chegaram mesmo a questionar se a Geografia seria uma ciência ou uma ideologia (SANTOS, 2004). Existiam razões bastante claras que os levaram a essas conclusões. A Geografia justificou a expansão colonial e imperialista europeia ${ }^{1}$, a dominação dos mais diversos povos e territórios, construiu discursos legitimadores do Estado-nação e ajudou a moldar e difundir os sentimentos patrióticos e nacionalistas. Em outro momento, foi transformada em um instrumento fundamental do planejamento estatal, sempre contribuindo com a manutenção dos interesses das classes dominantes (MOREIRA, 2008).

Em seguida, ou mesmo concomitantemente, passa-se a uma profunda crítica dos seus fundamentos epistemológicos. A Geografia não somente havia justificado a dominação de classe, a opressão e a exploração capitalistas como criara conceitos, métodos e categorias de análise que se tornaram verdadeiros obstáculos à compreensão da sociedade, de suas transformações e contradições. Lacoste (1997) fala da região como um conceito obstáculo, reflete sobre a dicotomia Geografia Física/Geografia Humana e apresenta a necessidade de um projeto unitário para a Geografia; Quaini (2002) de um compêndio fragmentário e caótico; e Claval pensa a Geografia como uma "disciplina feita pela justaposição de elementos cujas relações não se impõem com muita lógica”" (CLAVAL apud QUAINI, 2002: 11).

A obra de Neil Smith é uma das expressões do movimento de renovação crítica da Geografia. Em Desenvolvimento desigual: natureza, capital e a produção de espaço, publicado em $1984^{3}$, esse autor procura elaborar uma interpretação da produção capitalista do espaço baseada nos fundamentos lógicos da teoria do desenvolvimento desigual. Para tanto, não somente corrobora os argumentos em favor de uma teoria da produção do espaço, como também apresenta a concepção da produção da natureza.

Antes de analisar diretamente o espaço geográfico e, mais precisamente, a ideia de produção do espaço, é necessário fazer um breve comentário sobre a evolução e as rupturas no conceito "científico" de espaço. Smith busca nesse movimento as origens da possibilidade da existência conceitual independente das noções de espaço natural, espaço social e do próprio espaço geográfico. Portanto, o objetivo deste artigo é refletir sobre os elementos da análise de Smith que o levaram a essa conclusão e apresentar sua proposta de ressignificação das noções de espaço absoluto e espaço relativo. 


\section{As transformações do conceito de espaço: a progressiva abstração do espaço em relação à matéria e à sociedade}

A produção do espaço, de acordo com Smith, é um resultado lógico da produção da natureza. Produção, produção da natureza e produção do espaço são momentos articulados do processo geral de reprodução ampliada do modo de produção capitalista. Não obstante, assim como acontece com o conceito de natureza, uma compreensão real do espaço é dificultada pelo conjunto de significados generalizados que informam o senso comum pela ideologia ${ }^{4}$.

A concepção newtoniana e kantiana ${ }^{5}$ do espaço absoluto, do espaço como um receptáculo, um vácuo, uma condição primordial para a existência das coisas e a realização dos acontecimentos e eventos, tornou-se hegemônica nas ciências - ao menos até o princípio do século $X X$, quando Einstein apresentou suas teorias da relatividade restrita e da relatividade geral - e no pensamento em geral. Para Smith:

Não importa a perspectiva crítica que assumamos com relação ao conceito, é difícil de se escapar de algumas noções básicas de espaço - espaço como um campo, como um receptáculo, como simples vácuo. Hoje, em sociedades ocidentais, essa visão de espaço é virtualmente instintiva na linguagem comum (SMITH, 1988: 109).

Antes de Newton, tendiam a predominar as concepções relativas do espaço. A reflexão sobre o caráter absoluto ou relativo do espaço é um desdobramento do debate, filosófico e científico, sobre as relações entre a matéria, o espaço e o tempo. Em geral, os defensores do espaço absoluto admitem a primazia do espaço e do tempo em relação à matéria. Por sua vez, aqueles que reivindicam a noção de espaço relativo afirmam a dependência do espaço em relação à matéria. Nesse caso, o espaço é o produto das relações entre partes específicas da matéria, o espaço não é uma entidade independente. Em suma, grosso modo, o espaço absoluto é uma espécie de "vazio" primordial e o espaço relativo um sistema de relações entre objetos.

Smith observa que a querela sobre a relatividade ou a natureza absoluta do espaço foi trazida para a Geografia pela denominada New Geography. "Anteriormente, os geógrafos tendiam a confiar quase exclusivamente na concepção absoluta de espaço, mas uma visão mais ampla da questão acompanhou as inovações técnicas da Revolução Quantitativa" (SMITH, 1988: 110).

A história do conceito de espaço é marcada por uma progressiva abstração. Uma abstração não somente em relação à matéria, como também 
em relação à sociedade. Recorrendo a Robert Sack, em sua obra The concepts of space in social thought, de 1980, Smith assevera que as dicotomias espaçomatéria e espaço-sociedade, ou melhor, lugar-sociedade, não possuíam nenhum significado social para as sociedades primitivas ${ }^{7}$. Smith observa que:

Em primeiro lugar, a história do conceito é marcada por uma contínua abstração do espaço em relação a matéria. Esta distinção que fazemos atualmente não se aplicava às sociedades primitivas. $O$ espaço não era diferenciado da matéria, nem da força ou do poder, do homem ou de qualquer outra coisa. A unidade da natureza era completa; espaço, substância e significado eram uma coisa só (SMITH, 1988: 112).

Essas sociedades estavam fundamentadas em uma experiência total da natureza e do espaço. A unidade essencial entre o homem e a terra, o homem e a natureza, ainda não foi rompida. Na verdade, nesse momento, "é o lugar, $e$ não o espaço, que as pessoas vivenciam" (Id, Ibid: 113). A natureza e o lugar são os elementos básicos que dão coerência à existência e às relações sociais, tanto em sua dimensão material quanto simbólica. Não há uma distinção entre espaço físico e espaço social. Não existe, todavia, uma conceituação abstrata do espaço ${ }^{8}$. Desde já, fica claro o caráter histórico-lógico do argumento da progressiva abstração do conceito de espaço reivindicado por Smith.

Na Grécia antiga, filósofos como Pitágoras e, mais adiante, Platão e Aristóteles conseguiam conceber 0 espaço em termos mais abstratos. Entretanto, no pensamento de todos eles, mesmo que suas noções sejam razoavelmente distintas e que, secundariamente, uma concepção absoluta do espaço também estivesse presente, permanece a inseparabilidade do espaço e da matéria. Portanto, suas concepções do espaço inscrevem-se naquele campo de defesa da relatividade, da compreensão do espaço e do tempo como dimensões da existência da matéria.

Somente na obra de Newton emerge uma diferenciação clara entre o espaço absoluto e o espaço relativo. Ao indicar o caráter absoluto do espaço, ao concebê-lo como independente e anterior à matéria, Newton, no entanto, também elaborou um conceito de espaço relativo. Em Philosophiae Naturalis Principia Mathematica ${ }^{9}$, Newton afirma que:

Eu não defino tempo, espaço, lugar e movimento como sendo coisas conhecidas por todos. Somente devo observar que as pessoas comuns concebem aquelas quantidades não a partir de outras noções, mas da relação que elas estabelecem com os objetos sensíveis. 
E daí surgem certas idéias pré- concebidas, para cuja eliminação será conveniente distingui-las emabsolutas e relativas, verdadeiras e aparentes, matemáticas e comuns (...) O espaço absoluto, em sua própria natureza sem relação com qualquer coisa exterior, sempre permanece semelhante e imóvel. O espaço relativo é uma dimensão ou medida um tanto mutável dos espaços absolutos, que nossos sentidos determinam por sua posição em relação aos corpos (NEWTON apud SMITH, 1988: 111).

Na obra de Newton, o espaço torna-se uma completa abstração em relação à matéria e, também, em relação às sociedades ${ }^{10}$. $O$ espaço absoluto, verdadeiro, alcançado pela razão, é imóvel. Não obstante, as relações entre as partes específicas da matéria produzem uma "dimensão" ou "medida" dos espaços absolutos. São os espaços relativos, determinados pelos "sentidos". A diferença fundamental entre o espaço absoluto e o espaço relativo é dada pela oposição essencial entre a razão e os sentidos. Para Smith, essa completa abstração do espaço é o que permite, pela primeira vez, conceber outras modalidades de espaço, separadas do espaço absoluto, isto é, do espaço físico, pois "quando o espaço físico tornou-se absoluto, ele deixou atrás de si um 'espaço' conceitual que eventualmente seria preenchido por conceitos tais como o de 'espaço social" (SMITH, 1988: 114).

Essa forma como foram concebidos, por Newton, o espaço absoluto e o espaço relativo é um resultado histórico-lógico da produção da natureza. $\mathrm{O}$ conceito de espaço absoluto não é suficiente para explicar a atividade material humana. Enquanto matéria e espaço permanecem con-fundidos, essa mesma atividade não pode ser compreendida em abstração ao espaço físico. Como já foi mencionado, para as sociedades primitivas, onde sociedade e espaço conformavam uma unidade fundamental, essa separação não existia. À época de Newton, contudo, com o desenvolvimento do processo de produção da segunda natureza, era imperativo construir um conceito que explicasse as profundas transformações oriundas da atividade humana. A oposição entre primeira e segunda naturezas é a pedra angular para essa necessidade ${ }^{11}$. Como o espaço absoluto é imóvel, imutável e não pode ser alterado por essa atividade, pelas transformações entre as partes específicas da matéria pelo trabalho humano, os resultados da produção da segunda natureza devem ser associados a alguma modalidade de espaço relativo - subconjunto do espaço absoluto. Desse modo:

A separação do espaço relativo e do espaço absoluto ofereceu os meios pelos quais um espaço social poderia ser separado do espaço físico, sendo o espaço social definido não em relação a uma natureza primeira 
independente e exterior, mas a uma segunda natureza humanamente produzida. Como o espaço relativo de Newton é um subconjunto do espaço absoluto, o espaço social surgiu como um subconjunto diferenciado do espaço físico. Embora o surgimento do espaço social como um conceito separado tenha que ter esperado virtualmente, até que o subconjunto de espaço relativo abrangesse o conjunto que uma vez o continha, isso representa a origem de sua independência $(\mathrm{SMITH}, 1988$ : 115).

A princípio, poderiamos supor que o advento da teoria da relatividade de Einstein, ao propor uma concepção relativa do espaço e ao sugerir que o espaço absoluto é apenas um caso especial de espaço relativo, deveria resultar em uma inversão do processo de abstração do espaço, pois as relações espaciais são entendidas como um atributo da matéria. Entretanto, não foi esse 0 efeito. E essa contradição pode ser explicada pela forma com que cada uma das teorias do espaço, desde os gregos, foi associada à Geometria.

"Tanto para Platão como para Aristóteles, a Geometria é a cola que une o espaço à matéria. A Geometria é explicitamente uma abstração dos corpos físicos reais, ao mesmo tempo em que descreve a estrutura do espaço" (SMITH, 1988: 114). Newton não abandonou essa noção elaborada pelos filósofos gregos, porém, exatamente por isso, encontrou uma dificuldade em sua concepção do espaço absoluto. A Geometria euclidiana, base das reflexões sobre o espaço de Platão e Aristóteles, é diretamente verificável na concretude da existência material. O espaço absoluto, independente da matéria, perde, em última análise, seu fundamento lógico. Portanto, o espaço absoluto, de acordo com Newton, não necessita, por sua própria natureza, dessa verificação pela Geometria euclidiana. Esse é o impulso fundamental para o desenvolvimento das geometrias não euclidianas e, por conseguinte, da noção do espaço como um múltiplo $n$-dimensional ${ }^{12}$. Isto é, o espaço passou a ser compreendido a partir de "construções matemáticas puramente abstratas desligadas da experiência material" (Id, Ibid: 115).

Einstein lançou mão das geometrias não-euclidianas, ao apresentar a teoria da relatividade, e sua concepção do espaço, consequentemente, é absolutamente dependente da matemática que corresponde a esses tipos de Geometria. Portanto, somente conseguiu demonstrar a relatividade do espaço nos níveis subatômico ou na escala dos sistemas planetários. Dessa forma, o espaço físico é substituído pelo espaço matemático, aumentando o grau de Abstração ${ }^{13}$.

Esse alto grau de abstração do espaço em relação à matéria e, por conseguinte, à sociedade, como já foi sugerido, é o que permite o surgimento do conceito de espaço social em oposição ao espaço físico, absoluto. Mas,

TAMOIOS. ANO V. № 1, 2009 - ISSN 1980-4490 
para Smith, essa progressiva abstração possui um fundamento real, não é o simples resultado do desenvolvimento de especulações filosóficas. É o movimento "da progressiva dissociação do homem em relação ao território, após a transformação do território de valor de uso em valor de troca ou mercadoria"14 (QUAINI, 2002: 66) quem determina a progressiva abstração do espaço. Esse movimento pode ser apreendido nos termos da produção da natureza e, dessa maneira, Smith observa que:

A base material para a bifurcação do espaço físico e do espaço social está no desenvolvimento da segunda natureza a partir da primeira natureza. Na prática, a sociedade teve que ser separada da natureza antes que o espaço social pudesse ser completamente distinguido do espaço físico. Este espaço físico absoluto foi associado ao espaço natural da primeira natureza; aqui o espaço físico e o espaço natural são indistinguíveis (SMITH, 1988: 119-120).

A produção da natureza, da segunda natureza, a possibilidade da produção de um excedente permanente, o desenvolvimento das sociedades baseadas na troca de mercadorias, do Estado etc., isto é, "a história como separação do produtor ou trabalhador dos seus meios de produção e das suas condições de trabalho, ou seja a história como história da expropriação do homem em relação à natureza" (QUAINI, 2002: 66); tudo isso, enfim, é o fundamento material da progressiva abstração do espaço físico, agora compreendido como o espaço natural associado à primeira natureza, em contraste com o espaço social, domínio da segunda natureza. Mas, em geral, ao mesmo tempo em que o espaço físico ou natural foi se distanciando do espaço social, esse perdeu, na mesma medida, qualquer referência àquele, qualquer alusão à materialidade. Para Smith, talvez tenha sido de Émile Durkheim o mérito de primeiro utilizar o termo "espaço social", mas "ele foi cuidadoso ao insistir que o espaço social era completamente diferente e separado do espaço 'real', com o qual ele queria dizer espaço físico" (SMITH, 1988: 120). Isso leva Smith a afirmar que:

Assim como o espaço matemático veio representar o campo abstrato dos eventos naturais, o espaço social é o campo abstrato humanamente constituído pelos eventos sociais e pode ser definido de vários modos. Um objeto ou uma relação pode ser bastante real, por exemplo, a classe trabalhadora, ou a relação salário-trabalho, mas colocá-los como pontos no espaço social não implica absolutamente nada sobre sua localização no espaço físico ou no espaço natural (Id, Ibid: 120).

TAMOIOS. ANO V. № 1, 2009 - ISSN 1980-4490 
Dessa forma, surge a singularidade do espaço geográfico:

Agora o espaço geográfico é algo novamente diferente. Por mais social que ele possa ser, o espaço geográfico é manifestadamente físico; é o espaço físico das cidades, dos campos, das estradas, dos furacões e das fábricas. O espaço natural, no sentido de espaço absoluto herdado, não é mais sinônimo de espaço físico, haja vista que o espaço físico, por definição, pode ser social. Esta distinção surge no debate sobre o espaço geográfico, porque os geógrafos têm que lidar com 0 espaço físico em geral e não apenas com o espaço natural da primeira natureza (Id, Ibid: 120).

O espaço geográfico é social, contudo em um sentido diferente. $O$ espaço geográfico envolve não somente as determinações da segunda natureza - o mundo das relações humanas em oposição ao mundo natural como no caso do conceito de espaço social de Durkheim, mas, também, o espaço físico ou natural. No entanto, com o desenvolvimento da diferenciação entre a primeira e a segunda naturezas baseada na materialidade da primeira (valor-de-uso) e no caráter abstrato da segunda (valor e valor- de-troca), isto é, com o movimento de totalização do modo de produção capitalista e da produção da natureza em uma escala global, o espaço físico também é, ele mesmo, espaço social. O trabalho humano não é responsável somente pela unidade homem-natureza derivada da produção da natureza, mas pela unidade sociedade-espaço que resulta da produção social do espaço geográfico. A produção da natureza é, simultaneamente, produção do espaço. Encerra-se o dualismo essencial entre sociedade e espaço fundamentado na concepção newtoniana e kantiana do espaço absoluto.

\section{A produção capitalista do espaço em Neil Smith: ressignificando os conceitos de espaço absoluto e espaço relativo}

Em Geografia, o advento dessa nova compreensão do espaço social está associado ao movimento de renovação crítica, já mencionado na introdução deste artigo. Tanto a abordagem fenomenológica, quanto aquela fundamentada no materialismo historico e dialético elaboraram novas concepções do espaço social com o objetivo de superar os limites de uma abordagem baseada no conceito de espaço absoluto. A crítica amparada no marxismo, que Smith denomina de tradição política radical, teria apresentado os seguintes critérios para a elaboração de uma teoria geográfica do espaço 
social:

A preocupação não era negar a objetividade do espaço geográfico, mas explicá-lo como simultaneamente objeto e pro- duto de forças sociais. Diferentes sociedades usam e organizam o espaço de modos diferentes e os diferentes padrões geográficos daí resultantes ostentam o sinal evidente da sociedade que usa e organiza o espaço. A forma espacial da cidade capitalista, por exemplo, é completamente diferente da forma da cidade feudal (SMITH, 1988: 122).

Essas concepções pós-positivistas do espaço geográfico abriram caminho para uma renovação no conceito de espaço. Mas esses critérios acima destacados, na opinião de Smith, não são suficientes para que se deixe para trás, por completo, as noções tradicionais associadas ao espaço.

As primeiras tentativas da abordagem marxista, ainda segundo Smith, cometeram dois equívocos teóricos. Antes de tudo, quando se referem ao espaço geográfico, em alguma medida, como um "reflexo" da "interação" do espaço com a estrutura social, retrocedem ao dualismo e concebem "interação" como sinônimo de dialética ${ }^{15}$. Por outro lado, frequentemente, o espaço geográfico era incorporado à crítica marxista apenas como um meio de produção. O espaço geográfico funciona, de diversas formas, como um meio de produção, mas não pode ser reduzido a apenas isso ${ }^{16}$. Henri Lefebvre foi o primeiro autor a conceber o espaço não somente com um meio de produção ao atribuir-Ihe outras funções sociais:

A cidade, o espaço urbano e a realidade urbana não podem ser concebidos apenas como a soma dos locais de produção e de consumo... O arranjo espacial de uma cidade, uma região um país ou um continente aumenta as forças produtivas, do mesmo modo que o equipamento e as máquinas de uma fábrica ou de um negócio, mas em outro nível. Usa-se espaço exatamente como se usa uma máquina (LEFEVBRE apud GOTTDIENER, 1993: 128).

Smith reconhece na obra de Lefebvre a origem da concepção da produção do espaço, admitindo, inclusive, ter sido esse autor o primeiro a utilizar a expressão "produção do espaço". Smith, ao analisar as relações entre espaço e sociedade no processo histórico de estabelecimento de economias baseadas na troca de mercadorias, e, posteriormente, do modo de produção capitalista, utiliza a noção de produção do espaço para ressignificar os conceitos de espaço absoluto e espaço relativo. 
De acordo com Smith, com o advento do mercado e do Estado, as sociedades se tornaram simultaneamente mais fixas e mais móveis. A divisão entre campo e cidade, como consequência da separação entre agricultura e comércio, é o produto de uma emancipação em relação aos constrangimentos da situação espacial imediata. No entanto, "embora as próprias cidades sejam espacialmente fixas, as atividades que ocorrem dentro delas e as regras que comandam tais atividades sociais não são completamente fixas, espacialmente" (SMITH, 1988: 125). Emerge, desse modo, uma contradição fundamental. Segundo Smith:

Há aqui o gérmem de uma contradição. Com o objetivo de deitar raízes espaciais permanentes, isto é, obter definição territorial fixa, as sociedades primitivas devem desenvolver-se ao ponto em que possam começar a se libertar do espaço (...) Esta contradição é ainda mais evidente com o surgimento do Estado (Id, Ibid: 125).

O Estado destrói os fundamentos gentílicos das sociedades primitivas ${ }^{17}$ e é uma das expressões mais acabadas da segunda natureza. Se, por um lado, o Estado necessita estabelecer uma base territorial bem definida, por outro, o espaço torna-se um empecilho ao desenvolvimento social. Mas do que em quaisquer outras circunstâncias históricas anteriores, as regras e princípios sociais que regem os Estados, de acordo com Smith, são absolutamente abstratos e móveis. Encerra-se a unidade primordial entre o lugar e a sociedade. Com o desenvolvimento da complexificação social que resulta da generalização das relações mercantis e da forma estatal de organização social, é necessária uma expansão, e, nesse momento, expansão social e expansão geográfica são processos absolutamente correlatos. Os primeiros fundamentos de um mercado mundial de troca de mercadorias são estabelecidos. Fixação e mobilidade são os elementos fundamentais da dialética que orienta esse movimento.

O modo capitalista de produção, nos primeiros momentos de sua reprodução como uma totalidade que tende à universalidade, assimila esse movimento de generalização e expansão das relações mercantis e o potencializa. Mas o capitalismo necessita não somente generalizar as relações de troca, mas, fundamentalmente, as relações sociais de produção. Isto é, as relações sociais específicas entre o capital e o trabalho. A integração espacial é vital para o sucesso desse momento da totalização do modo de produção capitalista. A acumulação de capital, baseada na exploração de um número cada vez maior de trabalhadores despossuídos de meios de produção com o objetivo de transformar o valor na forma universal do trabalho abstrato ${ }^{18}$, é o fundamento material da tendência à universalização do capitalismo. De acordo 
com Smith:

Para o valor tornar-se a forma universal do trabalho abstrato como, de fato, ele busca fazer no modo capitalista de produção, diferentes processos de trabalho concreto, em lugares distintos, devem ocorrer conjuntamente no mercado. $O$ isolamento social dos processos particulares de trabalho, tão prejudicial à universalização do valor, não pode ser superado sem primeiro vencer 0 isolamento espacial dos diferentes processos $^{19}$ (SMITH, 1988: 128).

Desse modo, Smith é levado a afirmar que é "um erro interpretarem-se as análises de Marx sobre o capitalismo como sendo não-espaciais (...) seria mais exato dizer as vividas implicações espaciais das análises de Marx raramente foram reveladas" (Id, Ibid: 127). Smith recupera e resignifica os conceitos de espaço absoluto e espaço relativo, com base na análise do movimento de totalização do modo de produção capitalista, da integração entre os distintos espaços onde se realizam o trabalho concreto com o fito de convertê-lo em trabalho abstrato e na medida do valor. Para Smith:

Se retornarmos aos conceitos de espaço absoluto e espaço relativo e os examinarmos no contexto deste argumento, então surgirá mais alguma coisa importante. $\mathrm{Na}$ medida em que nos ativermos ao processo concreto do trabalho, nossa concepção de espaço será essencialmente absoluta. A particularidade do trabalho implica na particularidade de seus atributos espaciais. Com o trabalho abstrato, contudo, a situação é diferente. A realização do trabalho abstrato como valor implica em um sistema espacialmente integrado de troca de mercadorias (...) Isto requer a construção de elos específicos de transporte e de comunicação entre lugares individuais de produção concreta, e exige que sejamos capazes de conceber o espaço em termos relativos assim como em termos absolutos. A integração de um lugar de produção anteriormente isolado numa economia nacional ou internacional, por exemplo, não altera sua localização absoluta, mas no processo de modificação de sua posição relativa. Esse ato de integração espacial também au- menta a realização do trabalho abstrato como valor (Id, lbid: 129). 
Assim, Smith associa o espaço absoluto aos espaços da produção concreta de diferentes valores-de-uso e concebe o espaço em termos relativos quando sugere sua associação com a esfera da circulação dos valores-detroca e considera o movimento de universalização do valor como forma do trabalho abstrato. Em uma passagem igualmente extensa, mas tão necessária quanto a anterior para que fiquem claras as concepções do espaço absoluto e do espaço relativo e suas relações entre si e com as dimensões do valor-deuso e do valor-de-troca, ao comentar a obra de Smith, Moreira observa que:

O valor-de-uso remete ao espaço absoluto, com suas localizações fixas dos nichos de trabalho concreto e a ampla distribuição desses nichos numa extensão que se vai confundir com a divisão territorial do trabalho. Marx analisa-o ao detalhe no estudo do processo da produção. O valor-de-troca remete ao espaço relativo, esfera da transformação do trabalho concreto e seu valor-de-uso no trabalho abstrato e no valor-de- troca, respectivamente, completando na realização do valor. Marx analisa-o no estudo do processo da circulação. E o todo se integra no movimento conjunto do processo global da reprodução, em que o valor produzido no espaço absoluto aparece como a matéria-prima da produção do espaço relativo, e o espaço relativo, por sua vez, adquire a forma da esfera da circulação e das trocas, o mais-valor aí se realizando no lucro e daí voltando ao espaço absoluto para abrir o ciclo novo do eterno movimento reprodutivo (MOREIRA, 2009: 98).

Se o capital emancipou-se do espaço absoluto herdado - espaço natural - produzindo o espaço relativo, o fez produzindo novos espaços absolutos. Se, por um lado, "mais importantes se tornam as condições físicas da troca - os meios de comunicação e transporte" (MARX apud HARVEY, 2005: 50), por outro, ainda é necessário a existência dos espaços absolutos onde se realiza 0 trabalho concreto que produz valor. "Enquanto o capital deve, por um lado, esforçar-se em derrubar todas as barreiras espaciais para realizar o intercâmbio (...) em anular esse espaço pelo tempo" (Id, Ibid: 51), por outro, é imperativo que produza seus próprios espaços absolutos. Tanto o espaço absoluto quanto o espaço relativo são produtos da atividade, do trabalho humano e o espaço absoluto é um caso particular do espaço relativo.

Essa necessidade da produção de espaços absolutos está associada aos efeitos da busca incessante do capital por maiores rendimentos a partir dos mecanismos da mais-valia relativa ${ }^{20}$, do crescimento da composição organica do capital e do aumento da produtividade do trabalho em geral. Para promover o crescimento da produtividade do trabalho, o capitalismo necessita imobilizar

TAMOIOS. ANO V. № 1, 2009 - ISSN 1980-4490 
no espaço grandes quantidades de capital fixo ${ }^{21}$, o que corresponde a um crescimento da composição orgânica do capital. E a diferenciação espacial é um resultado desse processo. Para Smith:

A imobilização espacial do capital desta maneira, ou enquanto capitais nacionais delimitados pelas fronteiras da Nação- Estado, é simultaneamente a produção de um espaço geográfico diferenciado. $\mathrm{Na}$ medida em que a mobilidade do capital se iguala ao processo de imobilização, as tendências opostas se verificam, não ao acaso, mas numa diferenciação interna padronizada do espaço mundial. Portanto, à medida em que a produção do espaço ocorre, com o desenvolvimento do capitalismo, a contradição aparentemente abstrata entre o espaço absoluto e o espaço relativo se introduz cada vez mais na própria economia espacial do capitalismo (SMITH, 1988: 137).

Dessa forma, é possível compreender como duas tendências centrais se expressam na produção do espaço geográfico pelo capitalismo. Se, por um lado, o modo de produção capitalista é uma totalidade que tende à universalização, por outro, também é uma totalidade que se estrutura produzindo diferenciações e desigualdades. As tendências para a igualização e para a diferenciação como dois momentos distintos, porém simultâneos e interdependentes, da produção capitalista do espaço são as causas daquilo que Smith compreende como desenvolvimento desigual.

\section{Considerações finais}

Ao menos até o final do século XIX a expansão social do capitalismo se confundiu com sua expansão geográfica. No entanto, ao alcançar a produção global da natureza, ao atingir todos os rincões da superfície terrestre, o modo de produção capitalista estabelece as bases para suas próprias dificuldades de reprodução em um ritmo permanentemente crescente. Quando ainda era viável a expansão geográfica absoluta era possível para o capitalismo diminuir as tensões de suas contradições internas a partir da exteriorização. "Quando o desenvolvimento econômico se volta (...) rumo à diferenciação interna profunda do espaço geográfico, a dimensão espacial da contradição torna-se mais real (...) o espaço é atraído para perto do núcleo do capitalismo"22 (SMITH, 1988: 137). 
É sobre essa contradição da totalização do modo de produção capitalista que se quer refletir quando se afirma que o capitalismo vem sobrevivendo, ao longo de seu desenvolvimento, justamente a partir dos mecanismos da produção do espaço. Mas, quanto mais o espaço é atraído para o núcleo do capitalismo, quanto menos há a possibilidade de atenuar suas contradições pela exteriorização, tanto mais essa mesma produção do espaço toma uma importância decisiva para o capital ${ }^{23}$.

\section{Notas}

1- "As décadas finais do século $X I X$ marcam a passagem do capitalismo à sua fase superior: o imperialismo. E o nascimento do imperialismo traduzir-se-á, no plano da política internacional, como intensa luta entre as potências imperialistas pela divisão dos continentes em 'zonas de influência'. Dessa forma, a entrada do capitalismo em nova fase trará profundas transformações na geografia, no plano da realidade e, conseqüentemente, no plano do saber" (MOREIRA, 1988: 7). Para Santos: "A utilização da geografia como instrumento de conquista colonial não foi uma orientação isolada, particular a um país. Em todos os países colonizadores, houve geógrafos empenhados nessa tarefa, readaptada segundo as condições e renovada sob novos artifícios cada vez que a marcha da História conhecia uma inflexão (SANTOS, 2004: 31).

2- A primeira edição francesa de $A$ geografia - isso serve, em primeiro lugar, para fazer a guerra, de Yves Lacoste é de 1976, a primeira edição brasileira é de 1977. A primeira edição de Geografia e marxismo, de Massimo Quaini, foi publicada, na Itália, em 1974, tendo sido apresentada ao leitores brasileiros, pela primeira vez, em 1979 (MOREIRA, 2009).

3- A primeira e única edição brasileira é de 1988.

4- "Podemos especular que, em conexão com uma ideologia da natureza, estará uma ideologia do espaço" (SMITH, 1988: 33).

5- "Na Crítica da Razão Pura é proposto que se considere o espaço como a condição de possibilidade dos fenômenos e não como uma determinação deles resultante. Segundo a noção kantiana, o espaço é 'uma representação a priori, fundamento necessário dos fenômenos externos' (...) Aqui estamos bem mais próximos da noção do espaço absoluto de Newton, 'um receptáculo'" (SANTOS, Op.cit.: 50).

6- "Orientado pelo positivismo lógico (a filosofia da escola de Viena), o 
pressuposto da new geography é a presença de uma ordem estrutural matemática oculta por trás do padrão empírico de organização espacial dos fenômenos, cabendo-lhe descobrir e identificar as suas formas de manifestação. É esta descoberta que ao tempo que permite a explicação científica do fenômeno e dá à pesquisa o poder preditivo e nomotético que Ihe é necessário, confere a matéria da intervenção prática e o valor de cientificidade requeridos pela ação geográfica. A tarefa da Geografia como uma forma de ciência é, assim, descobrir e revelar esses padrões matemáticos, tal como requeria e recomendava Schaefer" (MOREIRA, 2009: 37).

7- Smith observa que Robert Sack sugere que o termo "primitivo" deve ser utilizado não em seu sentido pejorativo, mas com o significado de primazia histórica (SMITH, Op.cit.: 235).

8- "A etnologia nos mostra que as tribos primitivas são geralmente dotadas de uma percepção extraordinariamente aguda do espaço. Um nativo dessas tribos tem olhos para enxergar todos os detalhes mais minuciosos de seu ambiente. Ele é extremamente sensível a qualquer mudança na posição de objetos comuns em seus arredores. (...) Ao remar ou velejar segue com a maior precisão todas as curvas do rio que ele sobe ou desce. Mas, (...) Se você quiser que ele desenhe um mapa do rio, de suas curvas, ele parece até mesmo não entender a sua pergunta. Aqui compreendemos bem nitidamente a diferença entre a apreensão concreta e a apreensão abstrata do espaço e as relações espaciais" (CASSIRER apud SMITH, Op.cit.: 113).

9- Princípios Matemáticos da Filosofia Natural, publicado em 1687.

10- "Quando ele observou a queda da maçã, Newton não se indagou sobre as forças e os eventos sociais que levaram alguém a plantar a macieira nem sobre o traçado do jardim, ditando a localização precisa da maçã que caiu. Tampouco indagou ele acerca da domesticação das árvores frutíferas que deu à maçã sua forma" (SMITH, Op.cit.: 31).

11- A oposição entre primeira e segunda naturezas entendida, ainda, como a dicotomia entre o mundo não- humano e o mundo humano.

12- "A geometria surgiu na Grécia antiga, sistematizada por Euclides (e por isto chamada Geometria Euclidiana) em uma obra famosa, cuja influência perdurou até o século XIX. (...) As geometrias não-euclidianas começaram a surgir a partir da constatação da insuficiência da geometria Euclidiana para descrever a natureza real do espaço, bem como das tentativas constantes de demonstrar o chamado Quinto Postulado de Euclides, também conhecido como

TAMOIOS. ANO V. № 1, 2009 - ISSN 1980-4490 
Postulado das Paralelas" (ALVARENGA, 2009: 7- 171).

13- "O espaço tridimensional ou o espaço-tempo tetra-dimensional abriram caminho ao espaço matemático n-dimensional; o espaço físico é substituído pelo espaço matemático. Enquanto o conceito de espaço físico sempre conservou alguma referência à experiência humana prática, o espaço matemático é uma completa abstração para além daquele. A exigência de que a estrutura da realidade seja matemática pode ser verificada somente em referência aos fenômenos materiais na escala do sistema planetário ou na escala da física subatômica. Pois nem mesmo o físico matemático, que o dia todo mensura o universo em n-dimensões, não o conceberia, numa caminhada à loja da esquina, operando no espaço n- dimensional" (SMITH, Op.cit.: 116).

14- "Tempo e espaço tornaram-se abstratos sob o impacto da troca de mercadorias, sendo marcados por homogeneidade, continuidade e falta de todo conteúdo natural e material" (SOHN-RETHEL apud SMITH, Op.cit.: 118).

15- Sobre o espaço geográfico como um reflexo da sociedade, Santos assevera que: “(...) o espaço não é considerado como uma estrutura ou instância dotada de autonomia relativa, mas como um nível da sociedade, pelo fato de ser um reflexo das outras estruturas (...) Quando se considera o espaço como um mero reflexo, o estamos colocando sob o mesmo plano que a ideologia" (SANTOS, Op.cit.: 159). Se, por um lado, existem problemas na concepção um tanto estruturalista apresentada por Milton Santos em Por uma geografia nova, por outro, a crítica sobre o espaço geográfico como um reflexo da estrutura social permanece válida. Sobre a influência do estruturalismo nas primeiras concepções do espaço de Santos e a polêmica em torno à "espaciologia" ver Souza (1988).

16- "A importância do espaço geográfico como um meio de produção pode ser exemplificada concretamente, comparando-se o espaço consumido numa siderúrgica ou numa montadora de veículos com o espaço consumido numa padaria ou numa hidrelétrica. (...) Mas o fato de que o espaço geográfico pode funcionar como um meio de produção, não deve nos levar, como tem feito muitas vezes, a um tratamento rígido do espaço, somente como um meio de produção" (SMITH, Op.cit.: 134).

17- "Distinguindo-se da antiga organização gentílica, o Estado caracteriza-se, em primeiro lugar, pelo agrupamento de seus membros de acordo com uma divisão territorial' (ENGELS apud SMITH, Op.cit.: 125). Esta divisão territorial, segundo Engels, está em oposição à divisão determinada pelo parentesco. Essa abordagem de Engels pode estar na origem da concepção de Deleuze e Guattari sobre o surgimento do Estado como o primeiro grande movimento de

TAMOIOS. ANO V. № 1, 2009 - ISSN 1980-4.490 
desterritorialização. Segundo Haesbaert: "Ao contrário da maioria das interpretações, que vêem o Estado como uma espécie de 'fundador' da territorialização, pelo menos em seu sentido moderno, para Deleuze e Guattari - surgimento do Estado representa o primeiro grande movimento desterritorializador" (HAESBAERT, 2004: 137).

18- "O trabalho abstrato só é abstrato no sentido perfeitamente direto de que todas as características especiais que distinguem uma forma de trabalho de outra são ignoradas" (SWEEZY, 1982: 58).

19- "A riqueza abstrata, o valor, o dinheiro e, com eles, o trabalho abstrato, desenvolve-se na medida em que o trabalho concreto torna-se uma totalidade de diferentes modos de trabalho, abrangendo o mercado mundial" (MARX apud SMITH, Op.cit.: 129).

20- "Aumento obtido por uma redução da parte do dia (ou semana) de trabalho durante a qual o trabalhador reproduz o equivalente a seu salário sem uma redução global do dia (ou semana) de trabalho, o que se consegue através do aumento da produtividade do trabalho na agricultura e nos ramos da indústria que produzem bens de consumo para a classe operária" (MANDEL, 1982: 411). A concorrência em geral induz todos os capitalistas a aumentar a produtividade do trabalho, promovendo o desenvolvimento da técnica e o crescimento da composição orgânica do capital.

21- "Parte do capital constante utilizada para comprar prédios e máquinas" (Id, Ibid: 412).

22- "O traço característico do período em análise é a partilha final do globo final, não no sentido de que uma repartição seja impossível; pelo contrário, as redivisões são possíveis e inevitáveis - mas no sentido de que a política colonial dos países capitalistas tenha atingido os limites extremos dos territórios não ocupados em nosso planeta. Pela primeira vez, o mundo está completamente dividido, de maneira que no futuro somente a redivisão será possível, isto é, os territórios somente poderão passar de um 'dono' para outro, ao invés de passar da condição de território 'sem dono' para a de território de um proprietário" (LENIN apud SMITH, Op.cit.: 136).

23- "A idéia de que as coisas acontecem 'no espaço' não é somente um hábito do pensamento mas também um hábito da linguagem, e apesar de seu apelo ao absoluto, o espaço natural é anacrônico, até mesmo nostálgico e uma barreira a uma compreensão crítica do espaço. Por suas ações, a sociedade não mais aceita o espaço como um receptáculo, mas sim o produz; nós não vivemos, atuamos ou trabalhamos 'no' espaço, mas sim produzimos o espaço, 
vivendo, atuando e trabalhando" (SMITH, Op.cit.: 132).

\section{Referências Bibliográficas:}

ALVARENGA, Luis Gonzaga de. Geometria e imagem. Disponível em <http://www.scribd.com/doc/11599747/Geometria-Imagem> Acessado em 15 de dezembro de 2009.

GOTTDIENER, Mark. A produção social do espaço urbano. São Paulo: Edusp, 1993.

HAESBAERT, Rogério. O mito da desterritorialização: do "fim dos territórios" à multiterritorialidade. Rio de Janeiro: Bertrand Brasil, 2004.

HARVEY, David. A Produção Capitalista do Espaço. São Paulo: Anna Blume, 2005.

LACOSTE, Yves. A geografia - isso serve, em primeiro lugar, para fazer a guerra. São Paulo: Papirus, 1997.

MANDEL, Ernest. Capitalismo Tardio. São Paulo: Abril Cultural, 1982.

MOREIRA, Ruy. O que é a geografia. São Paulo: Brasiliense: 1988.

O pensamento geográfico brasileiro. As matrizes clássicas

originárias. São Paulo: Contexto: 2008.

O pensamento geográfico brasileiro. As matrizes da renovação.São Paulo: Contexto: 2009.

QUAINI, Massimo. Marxismo e Geografia. São Paulo: Paz e Terra, 2002.

SANTOS, Milton. Por uma geografia nova. São Paulo: EDUSP, 2004.

SMITH, Neil. Desenvolvimento desigual: natureza, capital e a produção de espaço. Rio de Janeiro: Bertrand Brasil, 1988.

SOUZA, M. L. "Espaciologia": uma objeção (crítica aos prestigiamentos pseudocríticos do espaço social). In: Terra Livre, n5. São Paulo: AGB-São Paulo, 1988. 
REVISTA TAMOIOS

SWEEZY, Paul. A teoria do desenvolvimento capitalista: princípios de economia política marxista. Rio de Janeiro: Zahar Editores, 1982.

TAMOIOS. ANO V. № 1, 2009 - ISSN 1980-4.90 